\title{
Avaliação do Curso de Biblioteconomia da Universidade Federal do Rio Grande - FURG: percepção dos discentes
}

\author{
Rodrigo Aquino de Carvalho \\ racfurg@gmail.com \\ Curso de Biblioteconomia, Universidade Federal do Rio Grande, Rio Grande, RS, Brasil
}

Cintia Kath Blank

Prefeitura Municipal do Rio Grande, RS, Brasil

cintiadabiblio@gmail.com

Andrei Steveen Moreno

wontola48@gmail.com

Programa de Pós-Graduação em Educação em Ciências, Universidade Federal do Rio Grande do Sul, Rio

Grande, RS, Brasil

Mauren Porciúncula Moreira da Silva

mauren@furg.br

Instituto de Matemática, Estatística e Física, Universidade Federal do Rio Grande, Rio Grande, RS, Brasil

Resumo: O trabalho apresenta uma avaliação do curso de Biblioteconomia da Universidade Federal do Rio Grande - FURG a partir da visão dos discentes matriculados em 2014. Os objetivos são: a) verificar o envolvimento dos estudantes com atividades extracurriculares; b) avaliar diversos aspectos do curso a partir de uma lista com 41 variáveis. O estudo é exploratório e quantitativo e para a coleta de dados foi utilizado um questionário. Os respondentes são 86 discentes, principalmente do sexo feminino (86,53\%), com idade entre 18 e 42 anos (72,09\%). Os principais resultados indicam que 59,30\% dos respondentes realizam ou realizaram pelo menos um tipo atividade extracurricular e o destaque, neste contexto, são estágios e projetos de extensão. Cinco componentes foram geradas, a partir de uma técnica de estatística multivariada - análise de componentes principais (ACP) -, sendo que as duas mais significativas são: aspectos relativos aos professores e ao ensino; e aspectos relativos à dedicação do aluno. Os pontos positivos são: disciplinas oferecidas, relevância dos conteúdos e conhecimentos dos professores sobre os conteúdos. Conclui-se que o curso é avaliado de forma positiva e que outras modalidades de atividades extracurriculares devem ser oferecidas. Sugere-se uma avaliação sistemática, principalmente com os concluintes ou recém-formados.

Palavras-chave: Avaliação de curso de graduação; Avaliação discente; Pesquisa quantitativa.

Evaluation of under graduation course Librarianship of the Federal University of Rio Grande - FURG: perception of students

Abstract: The paper presents an evaluation of under graduation course Librarianship at the Federal University of Rio Grande - FURG, from the vision of students enrolled in 2014. The objectives are: a) to verify student involvement in extracurricular activities; b) to evaluate diverse aspects of the course from a list of 41 variables. The study is exploratory and quantitative and the data collection was utilized a questionnaire. The respondents are 86 students, mostly female $(86.53 \%)$, aged between 18 and 42 years (72.09\%). The principal results indicate that $59.30 \%$ of respondents perform or have performed at least one type extracurricular activity and the highlight, in this context, are stages and extension projects. Five components were generated from a multivariate statistical technique - principal components analysis (PCA) -, and the two most significant are: aspects relating professors and teaching; and aspects relating to the dedication of the student. The positive aspects are subjects offered relevance of content and 
knowledge of professors on the contents. It is concluded that the course is assessed positively and other forms of extracurricular activities should be offered. It is suggested that the evaluation is systematic, mostly with students nearing completion of the course or recent graduates.

Keywords: Graduation course evaluation; Evaluation by students; Quantitative research.

Evaluación del curso de Biblioteconomía de la Universidad Federal de Rio Grande - FURG: la percepción de los estudiantes

Resumen: El artículo presenta una evaluación del curso de Biblioteconomía de la Universidad Federal de Rio Grande - FURG, desde la perspectiva de los estudiantes matriculados en el año 2014. Los objetivos son: a) comprobar la participación del estudiante en actividades extracurriculares; b) evaluar diversos aspectos del curso a partir de una lista de 41 variables. El estudio es exploratorio y cuantitativo. La recolección de datos se utilizó un cuestionario. Los entrevistados son 86 estudiantes, en su mayoría mujeres (86,53\%), con edades comprendidas entre los 18 y 42 años (72,09\%). Los principales resultados indican que $59,30 \%$ de los estudiantes realizan o han realizado al menos una actividad extracurricular tipo y el más destacado en este contexto son las etapas y proyectos de extensión. Cinco componentes se generaron a partir de una técnica estadística multivariante - análisis de componentes principales (PCA) y los dos más importantes son: los aspectos de los profesores y la enseñanza; y los aspectos de la dedicación de los estudiantes. Los aspectos positivos son: disciplinas ofrecidas, pertinencia de los contenidos y los conocimientos de los profesores sobre los contenidos. Se concluye que el curso es evaluado positivamente y otras formas de actividades extracurriculares deben ser ofrecidas. Se aconseja una evaluación sistemática, sobre todo con los estudiantes en la fase de finalización del curso o recién graduados.

Palabras clave: Evaluación del curso de graduación; Evaluación por los estudiantes; La investigación cuantitativa. 


\section{Introdução}

A avaliação do ensino superior no Brasil é de responsabilidade de diversos atores, o Ministério da Educação (MEC), as Instituições de Ensino Superior (IES), assim como os próprios cursos. No âmbito das políticas públicas e de regulação do ensino superior estão as avaliações externas e, no âmbito da melhoria institucional e das práticas educacionais, está a avaliação interna ou autoavaliação, que respeita a identidade, diversidade e contexto de cada instituição (VERHINE; FREITAS, 2012).

Dessa forma, torna-se cada vez mais necessário divulgar resultados de autoavaliação, para possibilitar análise de contextos amplos que auxiliem as IES e os cursos destas instituições na comparação com outras situações, na evolução de métodos e instrumentos para coleta e análise de dados e principalmente para diagnóstico das práticas nos cursos, com intuito de favorecer uma cultura avaliativa. Sendo assim, a avaliação precisa ser um processo, pois tem relação direta com qualidade e não deve ter como objetivo principal julgar ou denunciar, mas promover reflexões e melhorias nos contextos em que se insere (ASSOCIAÇÃO..., 2002).

Esse trabalho pretende identificar a opinião dos discentes do curso de Biblioteconomia da Universidade Federal do Rio Grande - FURG matriculados no curso em 2014. Caracteriza-se, portanto, segundo Pfeifer (2012) como uma avaliação interna e voluntária, qualitativa (não busca apresentar um indicador, mesmo sendo metodologicamente um trabalho quantitativo) e contextualizada. Para tanto, os objetivos do trabalho são: a) verificar o envolvimento dos estudantes com atividades extracurriculares; b) avaliar diversos aspectos do curso, a partir de uma lista com 41 variáveis qualitativas sem categorização.

Pretende-se também discutir sobre o método utilizado e o instrumento de coleta de dados. Uma das grandes dificuldades de promover processos avaliativos está na ênfase dada ao método, principalmente na relação entre as formas qualitativas e quantitativas. Assim, esse trabalho também pretende contribuir na adoção de métodos quantitativos para avaliação de cursos de Biblioteconomia utilizando uma técnica de estatística multivariada, explicada nos procedimentos metodológicos e colocando à disposição da comunidade da área o instrumento de coleta de dados ${ }^{1}$, para que possa ser reutilizado e melhorado.

Cabe assinalar que a Biblioteconomia, bem como da Ciência da Informação, estão em constante transformação. O objeto de estudo e trabalho dessa área é afetado de diversas maneiras pelos contextos social, cultural e tecnológico. Isso exige uma atenção especial na formação dos profissionais da informação, pois a educação é uma prática social que pode dinamizar outros processos sociais (ASSOCIAÇÃO..., 2001).

\footnotetext{
${ }^{1}$ Favor solicitar por e-mail.
} 


\section{Ensino superior: apontamentos}

A história da universidade no Brasil toma inicialmente um caráter metodológico engessado e ligado a concepções religiosas, no qual "[...] o conhecimento [é] tomado como algo posto, indiscutível, pronto e acabado [...]" (PIMENTA; ANASTASIOU, 2002, p. 146).

Nesse contexto, tornou-se historicamente comum que as IES primassem pelas atividades de ensino, baseadas, sobretudo, na cópia e na repetição de modelos, com viés pragmático e de cunho profissionalizante. À pós-graduação cabia a atividade de pesquisa, embora ainda muito deslocada para universidades do exterior. Segundo Tauchen (2009, p.54) somente na década de 1930, com o Estatuto das Universidades Brasileiras, é que as funções de pesquisa se aliam ao ensino, surgindo, juntamente com a extensão, o que hoje se denomina a tríade da indissociabilidade universitária: ensino-pesquisa-extensão.

Assim, percebe-se que, conceitualmente, o ensino superior em nosso país desenvolveu-se a partir de um viés predominantemente empirista para um contexto de construção e disseminação coletiva de conhecimentos. Neste sentido, professores e estudantes assumem a responsabilidade nos processos de ensino e de aprendizagem, no qual ambos devem ter participação a fim de melhor qualificar toda a estrutura universitária, a sociedade como um todo e cada indivíduo como um sujeito em permanente construção.

Nastri (1988) aponta, na década de 1980, que o ensino superior precisava responder duas questões importantes: o foco de sua função em formação cultural ou profissional e a extensão dessa função à sociedade. Essas questões ainda parecem atuais e as faculdades, os centros universitários e as universidades - que possuem objetivos distintos relacionados à educação superior - ainda precisam lidar com isso, principalmente pela multidiversidade e pluralidade que caracteriza a sociedade brasileira.

De maneira geral, a Lei de diretrizes e base da educação nacional - LDB (BRASIL, 1996) estabelece as seguintes finalidades que podem ser destacadas sobre o ensino superior no Brasil: estimular criação cultural, ciência e reflexão; formar diplomados em diversas áreas do conhecimento e promover a formação contínua direcionando-os para setores profissionais e para colaborar no desenvolvimento da sociedade brasileira; incentivar a pesquisa para desenvolver ciência e tecnologia; colaborar no entendimento do homem e no meio que vive; suscitar o desejo contínuo de aperfeiçoamento profissional e cultural dos indivíduos.

Uma faceta importante da reforma do ensino superior no Brasil, que a LDB (BRASIL, 1996) apresenta, é a flexibilização curricular, já que anteriormente os chamados "currículos mínimos" balizavam o conteúdo dos cursos de graduação. Assim, o ensino superior no Brasil caminhou no sentido de respeitar os contextos na ampliação da liberdade para os atores envolvidos na formação e essa condição exige ainda mais atenção à avaliação interna 
(VERHINE; FREITAS, 2012). A avaliação interna mede os processos, não apenas tomando como parâmetro os resultados obtidos, buscando um contraponto entre a função das universidades e os resultados (BOCLIN, 2005) que o Estado utiliza para criar rankings de reputação, como o Índice Geral dos Cursos - IGC (BITTENCOURT; CASARTELLI; RODRIGUES, 2009).

Catani, Oliveira e Dourado (2001) destacam ainda que, além das questões curriculares, a reforma proposta pela LDB permitiu aos cursos a adaptação às demandas do mercado de trabalho, a integração entre graduação e pós-graduação e a formação de competências e habilidades gerais. Almeida Júnior (2002) faz uma ressalva sobre a influência do mercado de trabalho como elemento norteador, pois a sociedade tem outros interesses que a formação superior precisa responder. Morin (2003) afirma que a educação contemporânea precisa desenvolver indivíduos que conheçam e se preocupem com a condição humana.

\section{0 ensino em biblioteconomia no Brasil e o curso de Biblioteconomia da FURG: aspectos gerais}

A Biblioteconomia é uma profissão com base empírica que consiste na administração e na gestão de bibliotecas e seus acervos, para atender as necessidades informacionais da sua comunidade alvo. Apesar de ser uma atividade antiga, a Biblioteconomia é vista como uma disciplina da Ciência da Informação, uma ciência social aplicada relativamente nova (década de 1940), que procura entender as propriedades da informação (conhecimento registrado), bem como seus produtos, analisando processos relativos à construção, à comunicação e ao uso desse bem na sociedade (LE COADIC, 1996).

No quadro 1 estão os principais marcos do ensino da Biblioteconomia no Brasil a partir da década de 1960 .

Quadro 1. Ensino de Biblioteconomia no Brasil, destacando o curso da FURG.

\begin{tabular}{|c|c|}
\hline DATAS & DESCRIÇÃO \\
\hline $1940-1961$ & Consolidação do modelo pragmático americano no surgimento das novas escolas. \\
\hline 1940 & $\begin{array}{l}\text { Transferência do curso da Pref. Municipal de São Paulo para a Escola Livre de } \\
\text { Sociologia e Política. }\end{array}$ \\
\hline 1942-1948 & Criação de mais seis cursos no Brasil. \\
\hline 1944 e & Reforma do curso da BN e Criação do Instituto Brasileiro de Bibliografia e \\
\hline 1954 & Documentação - IBBD ${ }^{2}$, respectivamente. \\
\hline $\begin{array}{r}1958 \text { e } \\
1961\end{array}$ & $\begin{array}{l}\text { Definição da Biblioteconomia como profissão liberal e de nível superior e criação da } \\
\mathrm{FEBAB}^{3} \text {, respectivamente. }\end{array}$ \\
\hline
\end{tabular}

\footnotetext{
${ }^{2}$ Atual Instituto Brasileiro de Informação em Ciência e Tecnologia (IBICT).
} 


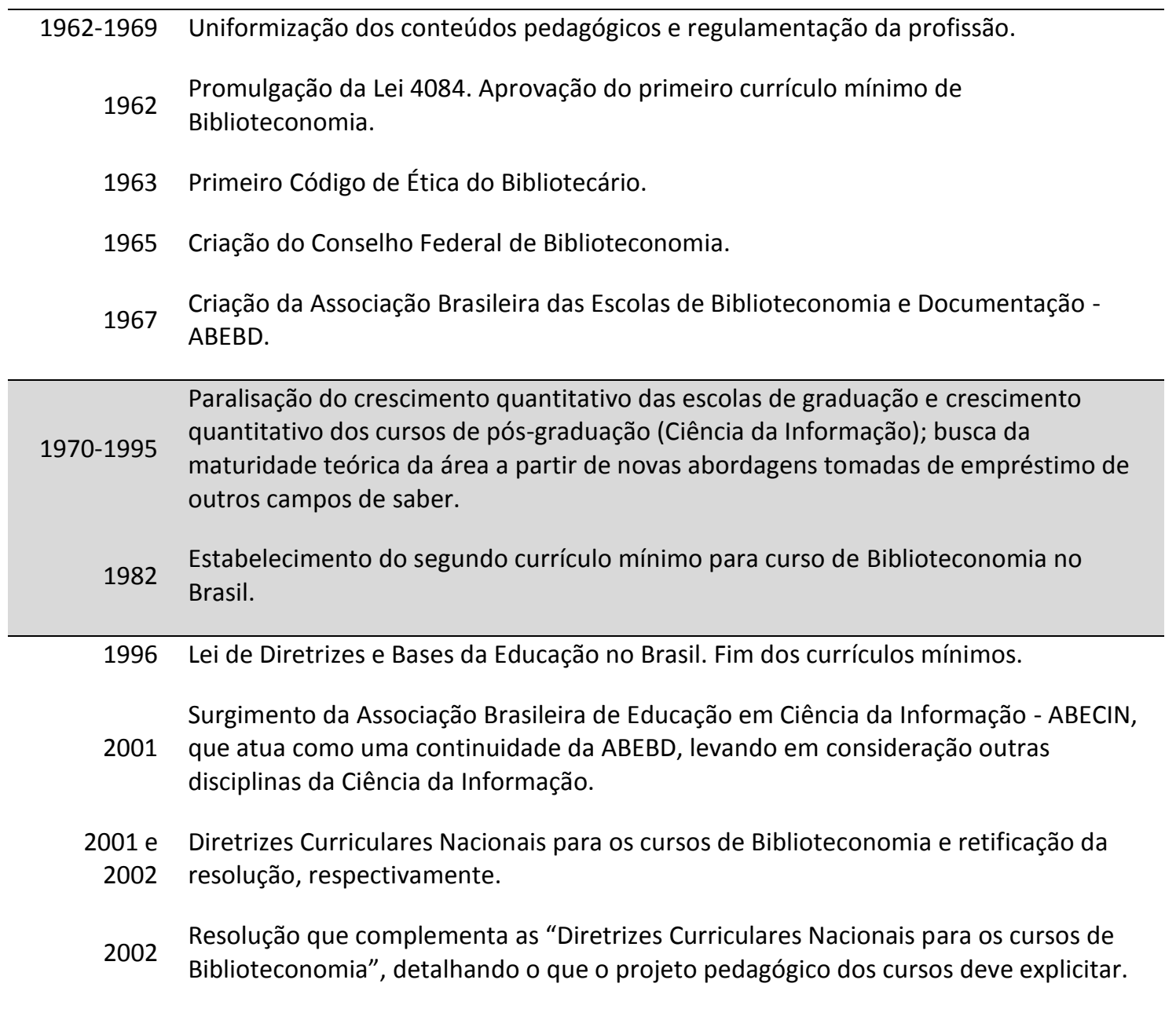

Fonte: Adaptado de Castro (2000) e ampliado de Conselho Nacional de Educação (BRASIL, 2001, 2002).

O Quadro 1 apresenta importantes fases do ensino em Biblioteconomia no Brasil, mas vale destacar aspectos relativos ao parecer do Conselho Nacional de Educação, de 2001, sobre as diretrizes curriculares para os cursos de Biblioteconomia (BRASIL, 2001), que enfatiza elementos mínimos genéricos para a formação do bibliotecário, a saber: atuação em diferentes tipos de unidades de informação, como centros culturais e patrimoniais; utilização de tecnologias de informação e comunicação; preparação para demandas personalizadas no relacionamento com os usuários; apresentação de respostas por demandas sociais; atuação como autônomo e necessidade de planejamento.

O mesmo parecer (BRASIL, 2001) indica que as escolas devem adotar uma perspectiva humanística para ampliar o cunho cultural e social da área, associar-se com outras áreas nas instituições, aumentar o núcleo de formação básica, além de criar ênfases em seus currículos, conforme a demanda e a disponibilidade.

\footnotetext{
${ }^{3}$ Federação Brasileira de Associações de Bibliotecários, Cientistas da Informação e Instituições.
} 


\subsection{Curso de Biblioteconomia da FURG}

O curso de Biblioteconomia da FURG foi criado em 1974 e a primeira turma iniciou o curso em 1975, formando-se em 1977 (CABERLON, 2001). Esse curso é resultado da interiorização do ensino que marca a Biblioteconomia brasileira na década 1970. Nesse período, o curso ainda respeitava o primeiro currículo mínimo de 1962 (CABERLON, 2001).

A primeira reforma curricular do curso Biblioteconomia da FURG aconteceu em 1984, atendendo o segundo currículo mínimo nacional para os cursos de Biblioteconomia, de 1982 (CABERLON, 2001; CARVALHO; MUCK; CORREA, 2013). Depois dessa reforma, que entrou em vigor em 1985, houve outra em 2000, que entrou em vigor em 2001 e uma em 2006, que entrou em vigor em 2007. Nessa última, foi definido o Projeto Político Pedagógico do curso Biblioteconomia da FURG, bem como as atividades com o Trabalho de Conclusão de Curso TCC (UNIVERSIDADE..., 2006).

Até 2014, o currículo do curso Biblioteconomia da FURG atende a quatro áreas temáticas: i) Fundamentos Teórico-Metodológicos da Biblioteconomia e Ciência da Informação; ii) Organização e Tratamento da Informação; iii) Recursos e Serviços de Informação; iv) Gestão da Informação (UNIVERSIDADE..., 2006). Sendo assim, acrescentando às áreas citadas outro eixo que poderia ser intitulado Formação Geral, o curso segue o perfil dos cursos de Biblioteconomia da Região Sul (BURIN, 2009). Vale salientar que o curso reformulou o currículo novamente, assim como o projeto pedagógico, que está vigente a partir de 2014 (UNIVERSIDADE..., 2013, 2015a), mas sem alterações que mereçam destaque para o escopo desse trabalho.

Até 2014, o curso da FURG formou 691 bacharéis em Biblioteconomia, sendo 89,58\% (619) do sexo feminino e 10,42\% (72) do sexo masculino (UNIVERSIDADE..., 2015b). Essa relação de gênero caracteriza a Biblioteconomia no contexto brasileiro, com apontam os estudos de Carvalho (2006) e Nastri (1988).

\section{Procedimentos metodológicos}

A pesquisa tem caráter exploratório e o método utilizado é essencialmente quantitativo, utilizando-se, para isso, de questionário semiestruturado para coleta de dados, composto por quatro partes: 1a) caracterização geral dos respondentes, incluindo a participação em atividades extracurriculares; 2a) indicação dos três principais motivos para ingresso no curso; $3^{\text {a }}$ ) escala de avaliação ${ }^{4}$ com 41 variáveis sobre diversos aspectos do curso e da sua infraestrutura, sendo que dois itens foram descartados na análise; e 4aa) duas questões

\footnotetext{
${ }^{4}$ Escala elaborada e ampliada a partir de um instrumento desenvolvido por discentes da disciplina "Pesquisa quantitativa em Educação" (Programa de Pós-Graduação de Educação em Ciências - PPGEC/FURG).
} 
finais, sendo uma aberta sobre os pontos fortes e fracos do curso $^{5}$, e uma fechada questionando se os discentes optariam pelo curso novamente.

A terceira parte do questionário é o foco principal do trabalho e as demais questões entraram para melhor caracterizar os sujeitos e ampliar a visão que os discentes possuem sobre o curso. Essa parte do questionário foi respondida a partir de uma escala do tipo Likert, de ' 5 ' (cinco) pontos, com valores entre ' 0 ' (zero) a ' 4 ' (quatro), sendo zero totalmente "ruim ou negativo", '2' (dois) "intermediário ou médio" e '4' (quatro) "totalmente bom ou positivo". A fim de verificar a consistência interna dos fatores e indicar confiabilidade das medidas foi calculado o coeficiente Alpha de Cronbach (MARTINS; THEOPHILO, 2009), que foi usado por Almeida, Pinto e Piccoli (2007) e por Batista et al (2013) para o mesmo fim.

Vale salientar que duas variáveis foram descartadas: "O horário do curso (matutino) interfere no meu desempenho"; e "O conhecimento sobre informática interfere no meu desempenho". Percebeu-se que alguns discentes entendiam as afirmações como influência positiva e outros como influência negativa e esse erro na construção, não percebido na adaptação do instrumento, ocasionou a necessidade de excluir tais variáveis da análise.

Os dados obtidos na terceira parte do questionário foram analisados a partir do software SPSS ${ }^{6}$, utilizando-se, para isso, de uma técnica de estatística multivariada chamada "análise de componentes principais" (ACP), que segundo Dansey e Reidy (2007) consiste em uma técnica que reduz um número de variáveis originais em componentes não relacionados $a$ priori, objetivando explicar a estrutura de variância e covariância de um vetor aleatório, ou seja, visando a diminuição de dados para facilitar a interpretação (ALMEIDA, PINTO E PICCOLI, 2007; ARTES, 1998). Vale destacar que elementos de estatística descritiva também foram usados para interpretar e analisar os dados apresentados nas mesmas variáveis.

A aplicação do questionário deu-se nas salas de aula situadas no campus Carreiros da FURG, entre os meses de maio e junho de 2014 , sendo que $56,95 \%$ dos alunos matriculados $(N=151)$ no curso responderam ao instrumento $(n=86)$. Vale salientar que em relação à variável aluno matriculado pode-se dizer que este não caracteriza discentes efetivos no curso, já que foi adotado o número oficial disponível no sistema da Universidade (UNIVERSIDADE..., 2014). Almeida, Pinto e Piccoli (2007) tiveram uma proporção parecida de respondentes - 53,5\% dos alunos matriculados para o caso do relato -, assim como Antunes, Polito e Resende (2010), que aplicaram um instrumento semelhante para $48 \%$ da população alvo.

\footnotetext{
${ }^{5}$ A análise dessa questão aberta exige um método qualitativo, e, portanto, não foi inclusa nesse trabalho que tem como foco aspectos metodológicos quantitativos.

${ }^{6}$ Statistical Package for the Social Sciences for Windows | Licença número: IBM SPSS v. 20.0 serie 10101121237.
} 
O número de respondentes, segundo Artes (1998), precisa ser de no mínimo 50 para validar uma ACP e o ideal é que para cada variável exista cinco respondentes, o que não ocorreu no trabalho, mas os dados apresentados, como as taxas de comunalidades ${ }^{7}$ das variáveis (Gráfico 1), a variância total explicada pelas componentes $(54,19 \%)$ e valor do coeficiente Alpha de Cronbach (Quadro 3) oferecem subsídio para o uso do método.

\subsection{Caracterização dos sujeitos da pesquisa}

Os discentes do curso de Biblioteconomia da FURG que participaram do presente estudo pertencem a quatro diferentes períodos (Tabela 1), sendo que $12,79 \%(n=11)$ não indicaram o ano que cursam. A maioria, 72,09\% ( $n=62$ ), possui idade entre 18 e 42 anos (Tabela 1), sendo a média de 32,64 anos de idade e a moda 22 anos. Pertencem ao gênero "feminino" $86,53 \%(n=77)$ dos respondentes, uma característica do curso (CARVALHO; MUCK; CORREA, 2013).

Tabela 1. Distribuição dos sujeitos por idade e gênero.

\begin{tabular}{|c|c|c|c|c|}
\hline \multirow{2}{*}{ Idade } & \multicolumn{2}{|c|}{ Gênero } & \multirow{2}{*}{\multicolumn{2}{|c|}{ Total por idade \% }} \\
\hline & Feminino & Masculino & & \\
\hline 18 a 22 & 21 & 03 & 24 & 27,91 \\
\hline 23 a 27 & 17 & 02 & 19 & 22,09 \\
\hline 28 a 32 & 08 & - & 08 & 9,30 \\
\hline 33 a 37 & 04 & 01 & 05 & 5,81 \\
\hline 38 a 42 & 04 & 02 & 06 & 6,98 \\
\hline 43 a 47 & 07 & 01 & 08 & 9,30 \\
\hline 48 a 52 & 10 & - & 10 & 11,63 \\
\hline 53 a 57 & 02 & - & 02 & 2,33 \\
\hline 58 a 62 & 02 & - & 02 & 2,33 \\
\hline 63 a 67 & 01 & - & 01 & 1,16 \\
\hline Sem resposta & 01 & - & 01 & 1,16 \\
\hline Total por gênero (\%) & $77-89,53 \%$ & $09-10,47 \%$ & 86 & $100,00 \%$ \\
\hline
\end{tabular}

Fonte: dados da pesquisa, 2015.

\footnotetext{
7 "As comunalidades são índices atribuídos às variáveis originais que expressam, em termos percentuais, o quanto da variabilidade de cada variável é explicada [...]. Quanto mais próximo de 1,0 estiver as comunalidades" (ARTES, 1998) melhor será a relação entre as variáveis em uma mesma componente.
} 
A Tabela 2 também indica o ano de conclusão do ensino médio dos respondentes. Nesse contexto, alunos do quarto ano $(n=27)$ foram os que mais responderam ao instrumento, mas houve uma distribuição equilibrada em relação ao número de respondentes dos outros anos e a maioria, $73,25 \%$ ( $n=63$ ), concluiu o ensino médio a partir de 2000.

Tabela 2. Distribuição dos sujeitos por ano de conclusão do ensino médio e ano no curso.

\begin{tabular}{|c|c|c|c|c|c|c|c|}
\hline \multirow{2}{*}{$\begin{array}{l}\text { Ano de conclusão no } \\
\text { ensino médio }\end{array}$} & \multicolumn{5}{|c|}{ Ano no curso } & \multirow{2}{*}{\multicolumn{2}{|c|}{$\begin{array}{c}\text { Total ano de } \\
\text { conclusão no ensino } \\
\text { médio (\%) }\end{array}$}} \\
\hline & 1응 Ano & 2ㅇ Ano & 3으o & 4ㅇ Ano & $\begin{array}{c}\text { Sem } \\
\text { resposta }\end{array}$ & & \\
\hline 1976 a 1989 & 01 & 02 & 01 & 03 & 01 & 08 & 9,30 \\
\hline 1991 a 1998 & - & 02 & - & 05 & 01 & 08 & 9,30 \\
\hline 2000 a 2005 & 02 & 04 & 04 & 10 & 02 & 22 & 25,58 \\
\hline 2006 a 2009 & 04 & 02 & 09 & 04 & 03 & 22 & 25,58 \\
\hline 2010 a 2013 & 07 & 05 & 02 & 02 & 03 & 19 & 22,09 \\
\hline Sem resposta & 01 & 02 & - & 03 & 01 & 07 & 8,14 \\
\hline \multirow{2}{*}{$\begin{array}{c}\text { Total ano do curso } \\
(\%)\end{array}$} & 15 & 17 & 16 & 27 & 11 & \multirow{2}{*}{86} & \multirow{2}{*}{100,00} \\
\hline & 17,44 & 19,77 & 18,60 & 31,40 & 12,79 & & \\
\hline
\end{tabular}

Fonte: dados da pesquisa, 2015

Além destas informações, outras questões foram abordadas a fim de melhor caracterizar os sujeitos, assim, levantaram-se os dados de que a maioria dos estudantes, $93,02 \%$ ( $n=80$ ) não possui outra graduação, enquanto que 4,65\% ( $n=04)$ são formados em outras áreas, sendo elas: "Sistemas para Internet", "Educação Física", "Estudos Sociais" e "Direito".

A Tabela 3 complementa o perfil dos respondentes. Rio Grande é a principal cidade de origem (65,12\%), mostrando que o curso de Biblioteconomia da FURG tem um perfil "local". Apenas 4,65\% ( $n=04)$ dos respondentes são de cidades de fora do estado do Rio Grande do Sul. 
Tabela 3. Distribuição dos respondentes por ano de ingresso no curso e cidade de origem.

\begin{tabular}{|c|c|c|c|c|c|c|c|c|c|c|}
\hline \multirow{2}{*}{ Cidade de origem } & \multicolumn{8}{|c|}{ Ano de ingresso no curso } & \multirow{2}{*}{\multicolumn{2}{|c|}{$\begin{array}{c}\text { Total por } \\
\text { cidades (\%) }\end{array}$}} \\
\hline & 2008 & 2009 & 2010 & 2011 & 2012 & 2013 & 2014 & Sem & & \\
\hline Rio Grande - RS & 01 & 05 & 03 & 14 & 07 & 11 & 12 & 03 & 56 & 65,12 \\
\hline Outras cidades do RS & - & - & 03 & 03 & 08 & 06 & 05 & - & 25 & 29,07 \\
\hline $\begin{array}{l}\text { Cidades de outros } \\
\text { estados }\end{array}$ & - & - & - & 01 & - & 01 & 02 & - & 04 & 04,65 \\
\hline Sem resposta & - & 01 & - & - & - & - & - & - & 01 & 01,16 \\
\hline \multirow{2}{*}{$\begin{array}{r}\text { Total por ano de } \\
\text { ingresso (\%) }\end{array}$} & 01 & 06 & 06 & 18 & 15 & 18 & 19 & 03 & \multirow{2}{*}{86} & \multirow{2}{*}{100,00} \\
\hline & 1,16 & 6,98 & 6,98 & 20,93 & 17,44 & 20,93 & 22,09 & 3,49 & & \\
\hline
\end{tabular}

Fonte: dados da pesquisa, 2015.

Finalizando os dados de perfil dos respondentes, foi indagado se estes possuíam emprego formal, relacionados ou não à Biblioteconomia. Nesta questão, 61,63\% ( $n=53)$ dos discentes declararam não possuir emprego formal, $29,07 \%(n=25)$ indicaram que possuem e $9,3 \%(n=08)$ não responderam ou foram inconclusivos nas respostas. Vale salientar que $8,14 \%$ ( $n=07)$ afirmam possuir emprego na área, sendo que estágios não foram considerados nessa questão, pois se trata de um tipo de atividade extracurricular.

\section{Resultados e discussão}

Os resultados de uma pesquisa por vezes mostram apenas o panorama circunstancial de um problema e, assim, generalizar nem sempre é possível e esse trabalho não tem essa pretensão. Os dados levantados visam apreender um panorama parcial do universo que se propõem a analisar, uma vez que $56,95 \%(n=86)$ dos matriculados responderam ao instrumento de coleta de dados. Um segundo elemento que colabora para aproximar os resultados aqui apresentados do contexto real em que estão situados é a distribuição equilibrada dos discentes entre os anos em que estão no curso (Tabela 2).

Os resultados serão apresentados e discutidos a partir dos próximos subtópicos.

\subsection{Motivos para a escolha e "se optariam pelo curso novamente".}

Os discentes foram questionados sobre quais são as três principais (em ordem de preferência) razões que os motivaram a escolher o curso de Biblioteconomia da FURG. As respostas de seis discentes foram completamente desconsideradas e 51 mais marcações, pois 
não cumpriam o que foi determinado pelo enunciado da questão. O Quadro 2 apresenta os dados válidos que foram organizados pela soma de marcação de cada razão, independentemente se foi a principal, a segunda ou a terceira razão mais significativa para a escolha do curso.

Quadro 2. Principais razões para a escolha do curso de Biblioteconomia da FURG.

\begin{tabular}{|c|c|c|c|}
\hline \multirow{2}{*}{ Razões que motivaram a escolha do curso } & \multicolumn{3}{|c|}{ Nível de motivos } \\
\hline & Principal & 20 & 3으 \\
\hline Identificação com o Curso & 29 & 10 & 11 \\
\hline Inserção no mercado de trabalho & 11 & 19 & 10 \\
\hline Realização pessoal & 12 & 11 & 12 \\
\hline A formação universitária aumentará minha competência profissional & 08 & 08 & 13 \\
\hline Prazer de aprender coisas novas & 08 & 09 & 11 \\
\hline Obtenção de diploma & 02 & 14 & 05 \\
\hline Interesse em ajudar os outros & 01 & 03 & 08 \\
\hline Não obtive aprovação em outro curso & 04 & 02 & 05 \\
\hline Outro & 02 & 00 & 01 \\
\hline
\end{tabular}

Fonte: dados da pesquisa, 2015.

O destaque fica para "identificação com o curso", como a principal razão. A razão "Inserção no mercado de trabalho" (item mais indicado como segunda razão de motivação) mostra a preocupação com empregabilidade. A razão "realização pessoal", como a terceira mais indicada, mostra que os discentes vislumbram na Biblioteconomia uma possibilidade que vai além da empregabilidade.

A Tabela 4 apresenta a distribuição dos discentes que optariam pelo curso novamente e mostra que $73,26 \%$ ( $n=63$ ) fariam essa escolha mais uma vez.

Tabela 4. Distribuição dos discentes que optariam pelo curso novamente.

\begin{tabular}{ccccccc}
\hline \multirow{2}{*}{ Ano no curso } & \multicolumn{3}{c}{ Optariam pelo curso novamente } & \multicolumn{2}{c}{ Total por ano no curso } \\
\cline { 2 - 5 } & Não & Sim & Sem resposta & & \\
\hline Primeiro ano & 03 & 11 & 01 & 15 & $17,44 \%$ \\
Segundo ano & 04 & 12 & 01 & 17 & $19,77 \%$ \\
\hline Terceiro ano & 04 & 12 & - & 16 & $18,60 \%$ \\
Quarto ano & 05 & 21 & 01 & 27 & $31,40 \%$ \\
\hline Sem resposta & 04 & 07 & - & 11 & $12,79 \%$ \\
\hline Total & $20-23,26 \%$ & $63-73,25 \%$ & $03-3,49 \%$ & 86 & $100,00 \%$ \\
\hline
\end{tabular}

Fonte: dados da pesquisa, 2015. 
Ao observar os dados, pode-se constatar que discentes de todos os anos afirmaram que não optariam novamente pelo curso e isso pode indicar que não existe uma causa específica relacionada ao tempo do discente no curso. Um estudo focado na motivação dos discentes e com estudantes evadidos podem apontar razões específicas.

\subsection{Atividades extracurriculares}

As atividades extracurriculares, como indicam as Diretrizes Curriculares dos Cursos de Biblioteconomia (BRASIL, 2002) são elementos importantes no processo de formação de um estudante de graduação e quanto mais atividades desse tipo são realizadas, mais ampla é essa formação, pois elas tendem a relacionar teoria e prática, aproximando o estudante da realidade do mercado de trabalho e de outras realidades da sua área de conhecimento.

Para o instrumento de coleta de dados foram definidas quatro categorias de atividades extracurriculares: monitoria e estágio (relacionadas ao ensino); pesquisa e extensão. A Tabela 5 apresenta a distribuição dos discentes que realizam ou realizaram atividades extracurriculares. Essa informação foi cruzada com o dado "ano no curso".

Tabela 5. Distribuição dos discentes que realizam ou realizaram atividades extracurriculares.

\begin{tabular}{|c|c|c|c|c|c|c|}
\hline \multirow{2}{*}{ Ano no curso } & \multicolumn{4}{|c|}{ Atividades Extracurriculares } & \multirow{2}{*}{\multicolumn{2}{|c|}{$\begin{array}{c}\text { Total por ano no } \\
\text { curso (\%) }\end{array}$}} \\
\hline & Sim & Não & Inconclusivo & Sem resposta & & \\
\hline Primeiro ano & 04 & 11 & - & - & 15 & 17,44 \\
\hline Segundo ano & 11 & 06 & - & - & 17 & 19,77 \\
\hline Terceiro ano & 13 & 03 & - & - & 16 & 18,60 \\
\hline Quarto ano & 18 & 06 & 03 & - & 27 & 31,40 \\
\hline Sem resposta & 05 & 05 & - & 01 & 11 & 12,79 \\
\hline \multirow{2}{*}{$\begin{array}{l}\text { Total das atividades } \\
\text { extracurriculares (\%) }\end{array}$} & 51 & 31 & 03 & 01 & \multirow{2}{*}{86} & \multirow{2}{*}{100,00} \\
\hline & 59,30 & 36,05 & 3,49 & 1,16 & & \\
\hline
\end{tabular}

Fonte: dados da pesquisa, 2015.

Os resultados mostram que $59,30 \%(n=51)$ afirmam estar envolvidos nesse tipo de atividade, sendo que a maioria é do quarto ano do curso e a minoria do primeiro. Muitos discentes realizaram mais de um tipo de atividade extracurricular e alguns até os quatro tipos. Estágio foi indicado 31 vezes, extensão 22, pesquisa 10 vezes, monitoria quatro vezes e não foi possível determinar cinco respostas. 
Parece interessante destacar nos resultados dois pontos: i) o pouco envolvimento com monitoria - atividade extracurricular que favorece a formação docente e ii) dos $36,05 \%$ ( $n=31$ ) dos que não realizaram atividade extracurricular, 11 já passaram da metade do curso e cinco são formandos. O trabalho pressupôs que os discentes conheciam modalidades de extensão e sua importância para responder a questão, já que atividades desse tipo favorecem a relação entre a instituição e sociedade, sendo basicamente seu objetivo a difusão de conhecimento e a prestação de serviços à comunidade (BRASIL, 2000/2001).

O último destaque dos resultados dessa parte fica para o estágio como atividade mais realizada, o que possibilita uma formação mais ampla do bibliotecário egresso do curso de Biblioteconomia da FURG, uma vez que, como afirma Buriolla (2009), o estágio pode ser onde a identidade profissional é formada.

\subsection{Escala de avaliação do curso de Biblioteconomia da FURG}

As respostas às 39 questões, da terceira parte do questionário, foram tabuladas e validadas no software SPSS. Após alguns passos e decisões limitou-se em cinco componentes principais a análise com 30 variáveis. O estudo de Batista et al (2013) mostra ser válido diminuir o número de variáveis e limitar o número de componentes.

O Quadro 3 mostra as taxas do Alpha de Cronbach para as três situações de análise no trabalho, mostrando a consistência dos dados. Segundo Martins e Theóphilo (2009) quanto mais próximo a 1,0 e acima de 0,7 melhor a confiabilidade dos dados. Cabe destacar que o Alpha de Cronbach na pesquisa de Almeida, Pinto e Piccoli (2007) apresentou resultado parecido, igual a 0,92, assim como a pesquisa de Batista et al (2013), com a taxa igual a 0,94.

Quadro 3. Taxas de Alpha de Cronbach apresentadas na análise.

\begin{tabular}{ccc}
39 variáveis & 32 variáveis & 30 variáveis (final) \\
0,898 & 0,884 & 0,881 \\
\hline
\end{tabular}

Fonte: dados da pesquisa, 2015.

Na ACP 30 variáveis foram consideradas, pois apresentavam taxas de comunalidades acima de 0,400 . As variáveis $01,07,11,15,16,17,29,31$ e 36 (Quadro 9) não foram aproveitas para a formação das CP por apresentar taxas de comunalidades abaixo de 0,400. Essa carga fatorial (comunalidade) mostra a força da correlação entre as variáveis com a variável mais forte da análise, como indicam Almeida, Pinto e Picolli (2007).

As 30 variáveis formaram cinco componentes (esse número foi limitado no software), que representam $54,19 \%$ da variância explicada, sendo a componente 01 a mais significada 
dessas categorias, explicando $26,92 \%$ da variância. A componente foi composta por 10 variáveis e nomeada "aspectos relativos aos professores e ao ensino".

Quadro 4. Componente 1-Aspectos relativos aos professores e ao ensino.

\begin{tabular}{|c|c|c|c|c|c|c|}
\hline & Variáveis & Comunalidade & Média & Mediana & Moda & $\begin{array}{l}\text { Desvio } \\
\text { padrão }\end{array}$ \\
\hline V06 & Relevância dos conteúdos das disciplinas & 0,719 & 3,00 & 03 & 03 & 0,89 \\
\hline V41 & Satisfação geral com o curso & 0,639 & 2,95 & 03 & 03 & 0,82 \\
\hline V04 & Avaliação proposta pelos professores & 0,634 & 2,64 & 03 & 03 & 0,97 \\
\hline V05 & $\begin{array}{r}\text { Estratégia de aula utilizada pelos } \\
\text { professores }\end{array}$ & 0,618 & 2,56 & 03 & 02 & 0,90 \\
\hline V30 & $\begin{array}{r}\text { Gosto das atividades que me fazem } \\
\text { pensar }\end{array}$ & 0,608 & 3,34 & 04 & 04 & 0,81 \\
\hline V18 & $\begin{array}{r}\text { Práticas de ensino utilizadas pelos } \\
\text { professores }\end{array}$ & 0,567 & 2,66 & 03 & 03 & 0,83 \\
\hline V21 & Disciplinas oferecidas pelo curso & 0,502 & 3,00 & 03 & 03 & 0,87 \\
\hline V03 & $\begin{array}{l}\text { Conhecimento dos professores sobre o } \\
\text { conteúdo das disciplinas que ministram }\end{array}$ & 0,496 & 3,20 & 03 & 04 & 0,84 \\
\hline V34 & Sou estimulado a participar das aulas & 0,501 & 2,67 & 03 & 03 & 1,06 \\
\hline V32 & $\begin{array}{r}\text { Existe integração e relação entre as } \\
\text { disciplinas }\end{array}$ & 0,462 & 2,93 & 03 & 03 & 1,01 \\
\hline
\end{tabular}

Média da componente $\quad 2,90$

Fonte: dados da pesquisa, 2015.

Essa componente aborda duas dimensões de avaliação para cursos de graduação, segundo documento oficial do Ministério da Educação (BRASIL, 2008), ou seja, versam tanto sobre o desenvolvimento das disciplinas quanto ao posicionamento dos professores como educadores. São eles: "organização didático-pedagógica e corpo docente", "discente e técnicoadministrativo". Podemos destacar nessa componente que "disciplinas oferecidas", "relevância dos conteúdos", "conhecimentos dos professores sobre os conteúdos" e "gosto dos discentes sobre atividades que os fazem pensar" foram consideradas "boas ou muito boas". Tanto no trabalho de Almeida, Pinto e Piccoli (2007), como no trabalho de Batista et al. (2013) as componentes mais significativas foram sobre o papel do docentes e questões curriculares.

As variáveis restantes ficaram acima de 2,0 (médio/regular), com destaques negativos para: "estratégias utilizadas pelos professores" (média mais baixa e moda igual a 2,0 ); "sou 
estimulado a participar das aulas" e "integração e relação entre as disciplinas", que tiveram boas médias, mas o desvio padrão mostra que alguns discentes as avaliaram negativamente.

Almeida (2014) mostra que o corpo docente do curso é formado por doutores recémformados, três a partir de 2010, sendo que um é mestre. Então, cabe ressaltar, que a qualificação dos docentes do curso deve melhorar alguns dos aspectos avaliados, além de possibilitar uma melhoria no domínio dos conteúdos. Ainda pode ser mencionado que a formação pedagógica parece ser necessária também e a pós-graduação em nível de mestrado e doutorado, por vezes, não prepara para o docente para dar aulas, mas sim para fazer pesquisa.

A Componente 02 reuniu cinco variáveis e foi denominada "aspectos relativos ao interesse do aluno".

Quadro 5. Componente 2 - Aspectos relativos à dedicação do aluno.

\begin{tabular}{|c|c|c|c|c|c|c|}
\hline \multicolumn{2}{|r|}{ Variáveis } & \multirow{2}{*}{$\begin{array}{c}\text { Comunalidade } \\
0,769\end{array}$} & \multirow{2}{*}{ Média } & \multirow{2}{*}{ Mediana } & \multirow{2}{*}{ Moda } & \multirow{2}{*}{$\begin{array}{c}\begin{array}{c}\text { Desvio } \\
\text { padrão }\end{array} \\
0,98\end{array}$} \\
\hline V37 & $\begin{array}{l}\text { Separo um tempo para estudar os } \\
\text { conteúdos e fazer as atividades em casa }\end{array}$ & & & & & \\
\hline V25 & $\begin{array}{r}\text { Tenho interesse em buscar } \\
\text { conhecimentos fora da sala de aula }\end{array}$ & 0,768 & 3,13 & 03 & 04 & 0,94 \\
\hline V24 & $\begin{array}{r}\text { Participo nas atividades propostas em } \\
\text { sala de aula }\end{array}$ & 0,752 & 3,20 & 03 & 04 & 0,80 \\
\hline V26 & Frequento as aulas & 0,682 & 3,44 & 04 & 04 & 0,70 \\
\hline V22 & $\begin{array}{l}\text { Tenho interesse em aprender os } \\
\text { conteúdos ministrados em aula }\end{array}$ & 0,675 & 3,32 & 03 & 04 & 0,80 \\
\hline \multicolumn{3}{|c|}{ Média da componente } & 3,19 & & & \\
\hline
\end{tabular}

Fonte: dados da pesquisa, 2015.

A componente aborda parte da dimensão de avaliação "corpo docente, discente e técnico-administrativo" (BRASIL, 2008). Podem-se caracterizar as variáveis como uma auto avaliação do discente, que pode ser considerada boa (média $=3,19$ ), com um destaque para a variável "separo tempo para estudar os conteúdos e fazer as atividades em casa", que foi a única com média inferior a 3,0. A componente mostra que os alunos são interessados em aprender os conteúdos, buscar conhecimentos fora da aula e que participam das atividades propostas.

Faz parte das atividades do curso e da universidade, de forma geral, estimular autonomia nos discentes. Carvalho, Muck e Correa (2013) mostram que apenas em 2010 o 
curso introduziu a pesquisa como atividade mais estreitamente relacionada ao ensino, através do da inserção do TCC. A pesquisa é talvez o principal elemento que estimula autonomia no aluno, mas as atividades relacionadas ao ensino também podem ser aproveitadas fora da sala de aula. Os docentes precisam perceber as limitações de aprendizado dos alunos e propor atividades que estimulem a busca por conhecimento fora da sala de aula.

A componente 03 é formada por cinco variáveis e foi denominada "aspectos extraclasse, infraestrutura e atendimento ao aluno".

Quadro 6. Componente 3 - Aspectos extraclasse, infraestrutura e atendimento ao aluno.

\begin{tabular}{|c|c|c|c|c|c|c|}
\hline & Variáveis & Comunalidade & Média & Mediana & Moda & $\begin{array}{l}\text { Desvio } \\
\text { padrão }\end{array}$ \\
\hline V19 & $\begin{array}{r}\text { Aplicabilidade das disciplinas } \\
\text { [atividades práticas] }\end{array}$ & 0,723 & 2,21 & 02 & 02 & 0,93 \\
\hline V13 & $\begin{array}{l}\text { Recursos oferecidos pelo } \\
\text { laboratório de informática }\end{array}$ & 0,717 & 2,59 & 03 & 03 & 0,94 \\
\hline V12 & $\begin{array}{l}\text { Atendimento oferecido pelos } \\
\text { funcionários da secretaria }\end{array}$ & 0,672 & 2,75 & 03 & 02 & 0,96 \\
\hline V33 & $\begin{array}{l}\text { Atuação e presença da } \\
\text { coordenação do curso }\end{array}$ & 0,614 & 2,72 & 03 & 03 & 1,11 \\
\hline V02 & $\begin{array}{l}\text { Interesse dos professores em } \\
\text { atender os alunos durante as aulas }\end{array}$ & 0,417 & 2,94 & 03 & 03 & 0,79 \\
\hline \multicolumn{3}{|c|}{ Média da componente } & 2,64 & & & \\
\hline
\end{tabular}

Fonte: dados da pesquisa, 2015.

A Componente 3 leva em consideração aspectos relacionados principalmente à infraestrutura da universidade ligada ao ensino e ao atendimento aos alunos. Essa foi a componente mais difícil de classificar e também a única que não apresentou nenhuma média igual ou acima de 3,0, apesar da média geral estar entre regular e boa. Aspectos relativos a "atividades práticas nas disciplinas" e "atendimento dos funcionários da secretaria" tiveram média igual a 02 (regular) e isso é um destaque negativo. Outro aspecto que merece destaque é a "atuação e presença do coordenador", mostrando uma discrepância maior entre quem considera essa variável ruim ou boa (desvio padrão $=1,11$ ). A componente apresenta uma relação com as três dimensões do "instrumento para a avaliação de cursos de graduação" (BRASIL, 2008).

Almeida, Pinto e Piccoli (2007) salientam, na pesquisa de auto avaliação da FURG, que os gestores da universidade precisam incentivar os docentes a estabelecer uma relação mais 
transparente e efetiva entre teoria e prática em suas atividades e essa necessidade parece ser uma reivindicação dos alunos do curso de Biblioteconomia. Souza e Reinert (2010), em um estudo qualitativo, também identificaram que os discentes de cursos superiores frequentemente consideram que falta conteúdo prático.

A componente 04 é composta por cinco variáveis e foi denominada "aspectos extraclasse relacionados ao conteúdo e à profissão".

Quadro 7. Componente 4 - Aspectos extraclasses relacionados ao conteúdo e à profissão.

\begin{tabular}{|c|c|c|c|c|c|c|}
\hline \multicolumn{2}{|r|}{ Variáveis } & \multirow{2}{*}{$\begin{array}{c}\text { Comunalidade } \\
0,662\end{array}$} & \multirow{2}{*}{$\begin{array}{l}\text { Média } \\
2,92\end{array}$} & \multirow{2}{*}{$\begin{array}{c}\text { Mediana } \\
03\end{array}$} & \multirow{2}{*}{$\begin{array}{c}\text { Moda } \\
03\end{array}$} & \multirow{2}{*}{$\begin{array}{c}\begin{array}{c}\text { Desvio } \\
\text { padrão }\end{array} \\
0,90\end{array}$} \\
\hline V09 & Currículo do curso & & & & & \\
\hline V08 & $\begin{array}{r}\text { Diversidade das atividades } \\
\text { extracurriculares oferecidas pela } \\
\text { instituição }\end{array}$ & 0,661 & 2,62 & 03 & 04 & 1,19 \\
\hline V10 & $\begin{array}{l}\text { Condições para ingresso na área } \\
\text { profissional [mercado de trabalho] }\end{array}$ & 0,568 & 2,82 & 03 & 03 & 0,85 \\
\hline V14 & Acervo disponível na biblioteca & 0,540 & 2,76 & 03 & 03 & 0,97 \\
\hline V20 & Qualificação dos professores & 0,429 & 3,34 & 03 & 03 & 0,68 \\
\hline & Méd & componente & 2,89 & & & \\
\hline
\end{tabular}

Fonte: dados da pesquisa, 2015.

As variáveis parecem um pouco distintas e essa foi outra componente difícil de classificar, pois leva em consideração "currículo", "empregabilidade" e "atividades extraclasse", além da "qualificação dos professores" e "acervo disponível na biblioteca". Apenas "qualificação dos professores" ficou com média acima de 3,0 (boa) e desvio padrão baixo, indicando respostas mais próximas da média. As demais variáveis são consideradas de regular para boa, com destaque para "diversidade das atividades extracurriculares", que apresentou mediana igual a 04, mas desvio padrão alto. Essa componente tem ligação com as dimensões de avaliação "organização didático-pedagógica" e "corpo docente, discente e técnico-administrativo" do "instrumento para a avaliação de cursos de graduação" (BRASIL, 2008).

A Componente 05 foi nomeada "aspectos relativos ao desempenho e envolvimento do aluno" e agrupou cinco variáveis. 
Quadro 8. Componente 5 - Aspectos relativos ao desempenho e envolvimento do aluno.

\begin{tabular}{|c|c|c|c|c|c|c|}
\hline & & Comunalidade & Média & Mediana & Moda & Desvio padrão \\
\hline V28 & $\begin{array}{l}\text { Desempenho nos trabalhos } \\
\text { propostos em sala de aula }\end{array}$ & 0,653 & 3,02 & 03 & 03 & 0,68 \\
\hline V27 & $\begin{array}{r}\text { Desempenho nas avaliações, } \\
\text { provas e trabalhos (notas) }\end{array}$ & 0,606 & 3,02 & 03 & 03 & 0,65 \\
\hline V40 & $\begin{array}{r}\text { Exponho todas as dúvidas } \\
\text { possíveis em aula, ainda que } \\
\text { pareçam "bobas" }\end{array}$ & 0,580 & 2,28 & 02 & 04 & 1,39 \\
\hline V39 & $\begin{array}{r}\text { Gosto das atividades em } \\
\text { grupo }\end{array}$ & 0,486 & 2,60 & 03 & 04 & 1,24 \\
\hline \multirow[t]{2}{*}{ V23 } & $\begin{array}{r}\text { Realizo atividades } \\
\text { extracurriculares relacionadas } \\
\text { ao curso }\end{array}$ & 0,484 & 2,23 & 02 & 04 & 1,58 \\
\hline & Média & da componente & 2,63 & & & \\
\hline
\end{tabular}

Fonte: dados da pesquisa, 2015.

A componente 05 tem uma relação estreita com a componente 02 , enquanto a última foca o interesse do discente, a quinta foca desempenho e envolvimento, e ambas podem ser entendidas como uma autoavaliação do discente, o que é pertinente para entender os dados. Os discentes consideram que o desempenho é bom (média acima de 3,0). As variáveis "expor dúvidas", "gosto por atividades em grupo" e "realização de atividades extracurriculares" estão com médias entre regular e bom, mas com moda igual a 04 e desvio padrão alto, indicando que as respostas estão mais distantes das médias. Essa componente mostra variáveis que se relacionam com as dimensões "organização didático-pedagógica" e "corpo docente, discente e técnico-administrativo" do "instrumento para a avaliação de cursos de graduação" (BRASIL, 2008) e isso evidencia que a avaliação se aproxima das categorias propostas pelo MEC.

\subsection{Variáveis não inclusas nas componentes}

O Quadro 9 reúne variáveis que avaliam o curso e que não entraram em nenhuma das componentes anteriormente apresentadas.

Quadro 9. Distribuição das variáveis não incluídas nas componentes.

\begin{tabular}{lccccc} 
& Variáveis & Média & Mediana & Moda & $\begin{array}{c}\text { Desvio } \\
\text { padrão }\end{array}$ \\
\hline \hline V01 & Relacionamento com os professores & 3,35 & 04 & 04 & 0,78 \\
V07 & Disponibilidade dos professores em atender os & 2,78 & 03 & 03 & 1,02
\end{tabular}




\begin{tabular}{|c|c|c|c|c|c|}
\hline \multicolumn{6}{|c|}{ alunos fora da sala de aula } \\
\hline V11 & Equipamentos audiovisuais disponíveis & 2,50 & 02 & 02 & 0,84 \\
\hline V15 & $\begin{array}{r}\text { Atendimento oferecido pelos funcionários da } \\
\text { biblioteca }\end{array}$ & 2,92 & 03 & 04 & 0,97 \\
\hline V16 & Estrutura física das salas de aula & 2,53 & 03 & 03 & 0,88 \\
\hline V17 & Limpeza das instalações & 3,17 & 03 & 03 & 0,87 \\
\hline V29 & $\begin{array}{r}\text { As monitorias ajudam no desenvolvimento das } \\
\text { disciplinas }\end{array}$ & 2,13 & 02 & 02 & 1,26 \\
\hline V31 & Gosto das atividades puramente práticas & 3,24 & 03 & 03 & 0,77 \\
\hline V36 & $\begin{array}{r}\text { Sou estimulado a pensar criticamente a área e a sua } \\
\text { função social }\end{array}$ & 2,65 & 03 & 03 & 1,10 \\
\hline
\end{tabular}

Fonte: Dados da pesquisa, 2015.

Algumas variáveis poderiam ser encaixadas em uma das cinco componentes, mas foi respeitado o limite do método e a análise feita pelo software utilizado. Como aspectos positivos pode-se destacar "relacionamento com os professores", "limpeza das instalações", que acompanham os resultados de Almeida, Pinto e Piccoli (2007) e "gosto dos discentes por atividades puramente práticas", com médias acima de 3,0, ou seja, uma avaliação de boa/bom para ótimo/muito bom. O destaque negativo foi a variável "ajuda das monitorias no desenvolvimento das disciplinas", que ficou com a média mais baixa de todas as variáveis $(2,13)$, além de mediana e moda igual a 02 , assim como "equipamentos audiovisuais disponíveis".

\section{Conclusões e apontamentos}

A partir dos objetivos indicados no trabalho, pode-se concluir que os discentes do curso de Biblioteconomia da FURG, que são majoritariamente do sexo feminino, com idade entre 18 e 42 anos, realizam ou realizaram atividades extracurriculares durante o curso (59,30\% dos respondentes), principalmente estágio e extensão, contexto este em que os itens de pesquisa e monitoria estão pouco citados. Parece necessário incluir os alunos em mais atividades de pesquisa e a qualificação dos docentes pode impulsionar essa prática.

Sobre os aspectos relacionados aos professores e ao ensino, pode-se concluir que a satisfação dos alunos é boa, com destaque para a percepção do conhecimento que os docentes possuem sobre os conteúdos, mas as estratégias em aula podem melhorar. Os discentes reconhecem a relevância dos conteúdos ministrados e o curso é avaliado como bom. 
Quanto à dedicação, envolvimento e desempenho dos próprios discentes, pode-se concluir que a avaliação ficou entre regular e boa, com destaque positivo para a frequência às aulas e interesse pelo conteúdo.

Observou-se que metodologicamente foi concretizada a validação do instrumento de coleta de dados com o auxílio da técnica de ACP o que possibilitou a identificação das categorias mais representativas do conjunto inicial de questões, expressando um grande número de dados de forma concisa, principalmente as duas primeiras componentes. Sendo assim, a relação entre o número de respondentes $(n=86)$ e o número de variáveis (30) pode ter interferido em uma formação mais adequada das componentes 3, 4 e 5. Vale ressaltar que a parte da estatística descritiva complementou satisfatoriamente o entendimento dos dados.

Reconhece-se que identificar o grau de satisfação dos alunos possibilita resultados parciais da análise dos dados obtidos. Dessa forma, torna-se necessário cruzar esses dados com a visão dos docentes, dos egressos e também dos empregadores, além de utilizar métodos qualitativos, como apresentou Souza e Reinert (2010), usando questões abertas no instrumento de coleta de dados.

Sugere-se que o instrumento utilizado nessa pesquisa seja ampliado e aplicado sistematicamente, principalmente nos discentes formandos ou em egressos (recém-formados), a cada quatro ou cinco anos e que um instrumento de coleta de dados qualitativo (questionário com questões abertas ou roteiro de entrevista) seja aplicado para buscar o entendimento mais amplo, assim como para buscar possíveis soluções. Parece fundamental que os docentes conheçam e utilizem métodos e técnicas para esse tipo de atividade, que envolve vocabulário e aplicativos específicos.

Além da autoavaliação focada nos processos, os cursos devem pensar na geração de indicadores próprios, pois como salienta Boclin (2005), os índices de conclusão, evasão e ocupação (empregabilidade), por exemplo, podem alinhar ações, comunicar com clareza o desempenho e, certamente, reforçam o planejamento nos cursos.

Por fim, espera-se que essa pesquisa possa trazer contribuições para o desenvolvimento de uma cultura avaliativa no curso de Biblioteconomia da FURG, como definem as diretrizes curriculares para os cursos no Brasil (BRASIL, 2002) e a Associação Brasileira de Educação em Ciência da Informação (ASSOCIAÇÃO..., 2002), e que seja um processo atrelado às atividades do corpo docente, da coordenação do curso e do núcleo docente estruturante ${ }^{8}$.

\footnotetext{
${ }^{8}$ A Comissão Nacional de Avaliação da Educação Superior (CONAES) definiu que cada curso precisa ter um Núcleo Docente Estruturante (NDE), que fica responsável pelo acompanhamento, processo de concepção, consolidação e contínua atualização do Projeto Pedagógico do Curso (PPC). Disponível em: http://goo.gl/jXHshz
} 


\section{REFERÊNCIAS}

ALMEIDA JÚNIOR, O. F. Formação, formatação: profissionais da informação produzidos em série. In: VALENTIM, Marta Lígia (Org.). Formação do profissional da informação. São Paulo: Polis, 2002. (Palavra-Chave, 13).

ALMEIDA, A. S. de. A epistemologia da prática docente: uma análise sobre os professores do curso de Biblioteconomia da Universidade Federal do Rio Grande (FURG). REBECIN, v.1, n.2, p.37-56, jul./dez. 2014. Disponível em: <http://goo.gl/7xUuZx>. Acesso em: 06 jul. 2015.

ALMEIDA, T. L. de; PINTO, S. S.; PICCOLI, H. C. Auto-avaliação na Fundação Universidade Federal do Rio Grande: metodologia de avaliação. Avaliação, Campinas, v. 12, n. 3, p. 515-530, set. 2007. Disponível em: <http://v.gd/o74ws2>. Acesso em: 19 jan. 2013.

ANTUNES, M. M.; POLITO, M. D.; RESENDE, H. G. de. Aspectos interferentes na qualidade do curso de Educação Física na ótica do corpo discente. Avaliação, Campinas, v. 15, n. 2, p. 163182, jul. 2010. Disponível em: <http://goo.gl/wu20UO>. Acesso em: 02 ago. 2015.

ARTES, R. Aspectos estatísticos da análise fatorial de escalas de avaliação. Revista de Psiquiatria Clínica, São Paulo, v. 25, n. 5, p. 223-228, 1998. Disponível em: <http://goo.gl/4PjrVj>. Acesso em: 02 ago. 2015.

ASSOCIAÇÃO BRASILEIRA DE EDUCAÇÃO EM CIÊNCIA DA INFORMAÇÃO - ABECIN. Avaliação da graduação em Biblioteconomia e Ciência da Informação: bases conceituais, metodológicas e princípios do processo avaliativo. Vitória: ABECIN, 2002. Disponível em: <http://goo.gl/KCkXGU>. Acesso em: 05 abr. 2015.

ASSOCIAÇÃO BRASILEIRA DE EDUCAÇÃO EM CIÊNCIA DA INFORMAÇÃO - ABECIN. Projeto pedagógico e avaliação da graduação: referências para a renovação e ressignificação do ensino em Biblioteconomia/Ciência da Informação. São Paulo: ABECIN, 2001. Disponível em: <http://goo.gl/B5Kag4>. Acesso em: 05 abr. 2015.

BATISTA, M. A. et al. Avaliação institucional no ensino superior: construção de escalas para discentes e docentes. Avaliação, Campinas, v. 18, n. 1, p. 201-218, mar. 2013. Disponível em: <http://goo.gl/Gm4D2E>. Acesso em: 02 ago. 2015.

BITTENCOURT, H. R.; CASARTELLI, A. de O.; RODRIGUES, A. C. de M. SOBRE O índice geral de cursos (IGC). Avaliação, Campinas, v. 14, n. 3, p. 667-682, nov. 2009. Disponível em: <http://goo.gl/wrhzDh>. Acesso em: 02 ago. 2015.

BOCLIN, R. Uso de indicadores de desempenho na avaliação institucional. Avaliação, Campinas; v. 10, n. 1, p. 121-132, mar. 2005. Disponível em: <http://goo.gl/txpSBo>. Acesso em: 02 ago. 2015.

BRASIL. Conselho Nacional de Educação. Parecer CNE/CES 492/2001. Diretrizes Curriculares Nacionais dos cursos de Filosofia, História, Geografia, Serviço Social, Comunicação Social, Ciências Sociais, Letras, Biblioteconomia, Arquivologia e Museologia. 2001. Disponível em: <http://goo.gl/Zg1MV3>. Acesso em: 04 abr. 2015. 
BRASIL. Conselho Nacional de Educação. Resolução CNE/CES 19/2002. Estabelece as Diretrizes Curriculares para os cursos de Biblioteconomia. 2002. Disponível em: <http://portal.mec.gov.br/cne/arquivos/pdf/CES192002.pdf>. Acesso em: 04 abr. 2015.

BRASIL. Fórum de Pró-Reitores de Extensão das Universidades Públicas Brasileiras e SESU/MEC. Plano Nacional de Extensão Universitária: edição atualizada. 2000/2001. Disponível em: <http://goo.gl/bMLahF>. Acesso em: 04 abr. 2015.

BRASIL. Lei no 9.394, de 20 de dezembro de 1996. Estabelece as diretrizes e bases da educação nacional. Disponível em: <http://goo.gl/TtBZb $>$. Acesso em: 07 dez. 2005.

BRASIL. Ministério da Educação. Portaria no 1,081, de 29 de agosto de 2008. Aprova, em extrato, o Instrumento de Avaliação de Cursos de Graduação do Sistema Nacional de Avaliação da Educação Superior - SINAES. 2008. Disponível em: <http://goo.gl/FLijQR>. Acesso em: 27 mar. 2013.

BURIN, C. K. O ensino de Biblioteconomia na Região Sul do Brasil: análise dos projetos pedagógicos dos cursos à luz das diretrizes curriculares nacionais. Florianópolis, 2009. Dissertação (Mestrado - Ciência da Informação) - Univ., Federal de Santa Catarina. 2009.

BURIOLLA, M. A. F. O estágio supervisionado. 6. ed. São Paulo: Cortez, 2009.

CABERLON, V. I. O Curso de Biblioteconomia da FURG: trajetos em revista. Biblos, Rio Grande, v. 13, p. 159-170, 2001. Disponível em: <http://v.gd/ltuxul>. Acesso em: 18 mar. 2013.

CARVALHO, R. A. de. Formação e atuação profissional do egresso da Faculdade de Biblioteconomia da PUC-Campinas de 1995 a 2005. Campinas, 2006. 117f. Monografia (Graduação) - Ciência da Informação com habilitação em Biblioteconomia, PUC-Campinas. 2006

CARVALHO, R. A. de; MUCK, F. A. L.; CORREA, S. S. Bacharelado em Biblioteconomia da Universidade Federal do Rio Grande - FURG: delineando parâmetros para uma avaliação. In: CONGRESSO BRASILEIRO DE BIBLIOTECONOMIA, DOCUMENTAÇÃO E CIÊNCIA DA INFORMAÇÃO - CBBD XXV. Anais... Florianópolis, 2013. Disponível em: <http://portal.febab.org.br/anais/article/viewFile/1501/1502>. Acesso em: 14 ago. 2014.

CASTRO, C. A. História da biblioteconomia brasileira. Brasília: Thesaurus, 2000.

CATANI, A. M.; OLIVEIRA, J. F.; DOURADO, L. F. Política educacional, mudanças no mundo do trabalho e reforma curricular dos cursos de graduação no Brasil. Educação \& Sociedade, a.22, n.75, p.67-83, ago/2001.

DANSEY, C. P.; REIDY, J. Estatística sem matemática para Psicologia: usando SPSS para Windows. 3. ed. Porto Alegre: Artmed; Bookman, 2007.

LE COADIC, Y.-F. A Ciência da Informação. Brasília: Briquet de Lemos Livros, 1996.

MARTINS, G. de A.; THEÓPHILO, C. R. Metodologia da investigação científica para ciências sociais aplicadas. São Paulo: Atlas, 2009.

MORIN, E. Os sete saberes necessários à educação do futuro. 8.ed. São Paulo: Cortez, 2003. 
NASTRI, R. M. Formação e atuação dos egressos da escola de Biblioteconomia e Documentação de São Carlos: um estudo de avaliação (1959-1985). 1988. 342f. Dissertação (Mestrado em Biblioteconomia) - Departamento de Pós-Graduação da Faculdade de Biblioteconomia, Pontifícia Universidade Católica de Campinas, Campinas, 1988.

PFEIFER, M. Dicotomias conceituais da avaliação da educação superior. Avaliação, Campinas, v. 17, n. 2, p. 351-364, jul. 2012. Disponível em: <http://goo.gl/6lnJvm>. Acesso em: 02 ago. 2015.

PIMENTA, S. G.; ANASTASIOU, L. das G. C. Tornar-se professor universitário hoje. In: Docência no ensino superior. São Paulo: Cortez, 2002. p. 141-157.

SOUZA, S. A. de; REINERT, J. N. Avaliação de um curso de ensino superior através da satisfação/insatisfação discente. Avaliação, Campinas, v. 15, n. 1, p. 159-176, mar. 2010. Disponível em: <http://goo.gl/tcWMxn>. Acesso em 02 ago. 2015.

TAUCHEN, G. O princípio da indissociabilidade universitária: um olhar transdisciplinar nas atividades de ensino, pesquisa e extensão. 2009. 146 f. Tese (Doutorado em Educação) Faculdade de Educação, PUC-RS, Porto Alegre, 2009.

UNIVERSIDADE FEDERAL DO RIO GRANDE. Conselho de Ensino, Pesquisa e Extensão e Administração. Deliberação no 087, de 23 de agosto de 2013. Dispõe sobre alteração curricular no curso de graduação em Biblioteconomia. Rio Grande: [s.n.], 2013. Disponível em: <http://www.conselho.furg.br/delibera/coepea/08713.htm>. Acesso em: 04 mar. 2015.

UNIVERSIDADE FEDERAL DO RIO GRANDE. Comissão de Curso de Biblioteconomia. Projeto Político Pedagógico do Curso de Biblioteconomia da FURG. Rio Grande: [s.n.], 2006.

UNIVERSIDADE FEDERAL DO RIO GRANDE. Coordenação de Curso de Biblioteconomia. Projeto Pedagógico do Curso de Biblioteconomia da FURG. Rio Grande: [s.n.], 2015a. Disponível em: <https://goo.gl/Zms7v1 >. Acesso em: 04 mar. 2015.

UNIVERSIDADE FEDERAL DO RIO GRANDE. Sistema de Informações Acadêmicas. Rio Grande: [s.n.], [2014]. Disponível em: <http://goo.gl/G4vlAt>. Acesso em: 10 ago. 2014.

UNIVERSIDADE FEDERAL DO RIO GRANDE. Sistema de Informações Acadêmicas. Rio Grande: [s.n.], [2015b]. Disponível em: <http://goo.gl/G4vlAt>. Acesso em: 04 mar. 2015.

VERHINE, R. E.; FREITAS, A. A. da S. M. de. A avaliação da educação superior: modalidades e tendências no cenário internacional. Revista Ensino Superior Unicamp, Campinas, 2012. Disponível em: <https://goo.gl/ljQf3O>. Acesso em: 02 ago. 2015. 